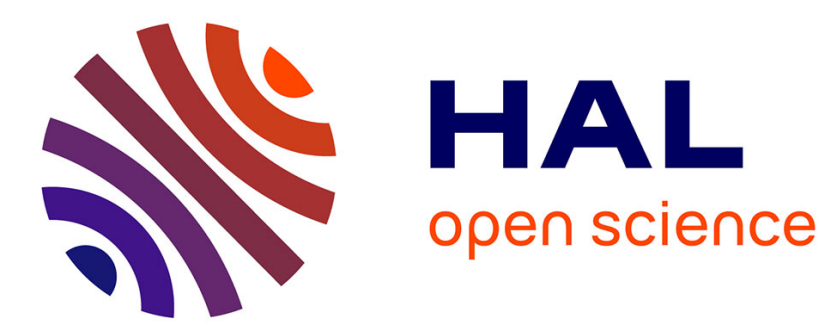

\title{
Crystal structure determination and thermal behavior upon melting of p-synephrine
}

Frédéric Rosa, Philippe Négrier, Yohann Corvis, Philippe Espeau

\section{To cite this version:}

Frédéric Rosa, Philippe Négrier, Yohann Corvis, Philippe Espeau. Crystal structure determination and thermal behavior upon melting of p-synephrine. Thermochimica Acta, 2016, 632, pp.18-22. 10.1016/j.tca.2016.03.010 . hal-01344306

\section{HAL Id: hal-01344306 https://hal.science/hal-01344306}

Submitted on 11 Jul 2016

HAL is a multi-disciplinary open access archive for the deposit and dissemination of scientific research documents, whether they are published or not. The documents may come from teaching and research institutions in France or abroad, or from public or private research centers.
L'archive ouverte pluridisciplinaire HAL, est destinée au dépôt et à la diffusion de documents scientifiques de niveau recherche, publiés ou non, émanant des établissements d'enseignement et de recherche français ou étrangers, des laboratoires publics ou privés.

\section{다(1)(2)}

Distributed under a Creative Commons Attribution - ShareAlikel 4.0 International 


\title{
Crystal structure determination and thermal behavior upon melting of $p$-synephrine
}

\author{
Frédéric Rosa ${ }^{\mathrm{a}}$, Philippe Négrier ${ }^{\mathrm{b}}$, Yohann Corvis ${ }^{\mathrm{a}}$, Philippe Espeau ${ }^{\mathrm{a}, *}$ \\ a Unité de Technologies Chimiques et Biologiques pour la Santé, U1022 INSERM, UMR8258 CNRS, Faculté des Sciences Pharmaceutiques et Biologiques, \\ Université Paris Descartes, Sorbonne Paris Cité, 4 Avenue de l'Observatoire, 75006 Paris, France \\ ${ }^{\mathrm{b}}$ Laboratoire Ondes et Matière d'Aquitaine, Université de Bordeaux, UMR CNRS 5798, 351 cours de la Libération, 33405 Talence Cedex, France
}

Keywords:

Enantiomer

X-ray powder diffraction

Crystal structure

Thermal analysis

Melting point

\begin{abstract}
A B S T R A C T
The crystal structure of $p$-synephrine was solved from a high-resolution X-ray powder diffraction pattern optimized by energy-minimization calculations using the Dreiding force field. The title compound crystallizes in a monoclinic system (space group $\mathrm{P} 2{ }_{1} / \mathrm{c}, \mathrm{Z}=4$, with $\mathrm{a}=8.8504(11) \AA, \mathrm{b}=12.1166(15) \AA$, $c=9.7820(11) \AA, \beta=122.551(2)^{\circ}, V=884.21(19) \AA^{3}$ and $\left.d=1.256 \mathrm{~g} \mathrm{~cm}^{-3}\right)$. Since $p$-synephrine degrades upon melting, its melting data were determined from DSC experiments carried out as a function of the heating rate. This method allowed determining a melting temperature and enthalpy equal to $199.8 \pm 1.3^{\circ} \mathrm{C}$ and $57 \pm 3 \mathrm{~kJ} \mathrm{~mol}^{-1}$, respectively.
\end{abstract}

\section{Introduction}

Synephrine, and more specifically $p$-synephrine, 4-[1-hydroxy2-(methylamino) ethyl]phenol, is an alkaloid that is naturally contained in some plants [1]. It is one the most popular stimulants present in weight-loss products, becoming the main substitute of ephedrine after this latter was banned in the dietary products by the Food and Drug Administration. The market of these products is flourishing, this results that many counterfeit products containing synephrine arose. The effects of synephrine are close to those of caffeine or ephedrine: increase of blood pressure and heart rate. This cardiotoxicity may be enhanced when it is combined with other stimulants, as previously reported [2]. A low subchronic toxicity and possible side effects such as reduction in locomotor activity have also been reported $[1,3]$.

$P$-Synephrine is the para isomer of synephrine. It is a crystalline racemate the chirality of which is due to the presence of a sp3-hybridized carbon with four different moieties, including the hydroxyl group (Scheme 1). Hence, two enantiomers, the dextrorotatory (D-) and the levorotatory ( $\left.\mathrm{L}^{-}\right)$synephrine, as well as the equimolar mixture between the two enantiomers are encountered.

\footnotetext{
* Corresponding author.

E-mail address: philippe.espeau@parisdescartes.fr (P. Espeau).
}

The D-isomer corresponds to the s-configuration, and the levorotatory L-isomer to the r-configuration.

However, very few data are available regarding the solid state of $p$-synephrine. For instance, its crystal structure has never been reported. It is therefore not possible to decide on the type of crystalline racemates: conglomerate, racemic compound or pseudoracemate. Then, the first aim of the present work is the refinement of the crystal structure obtained from X-ray powder diffraction experiments carried out at room temperature.

Similarly, from a thermodynamic point of view, very few thermal data are available regarding the melting characteristics [4-6]. Some authors give a melting temperature value approximately equal to $184-185^{\circ} \mathrm{C},[4,5]$ and another one reports a melting point of $186-187^{\circ} \mathrm{C}$ with decomposition upon melting [6]. But no indication is given on the measurement technique of the melting point and no enthalpy value has been determined. More recently, a DSC study carried out at $10^{\circ} \mathrm{C} \mathrm{min}^{-1}$ reports that synephrine melts at $190.53^{\circ} \mathrm{C}$ with a $99.7 \mathrm{~kJ} \mathrm{~mol}^{-1}$ associated enthalpy [7]. However, the authors suspect that the product degrades upon melting in these experimental conditions. Consequently, the reported enthalpy value does include the heat of fusion as well as a part of the heat of degradation.

To overcome this lack of information, differential scanning calorimetry (DSC) and thermogravimetric analysis (TGA) were conducted on commercial $p$-synephrine in order to determine if degradation occurs during melting and then, to propose accurate 
<smiles>CNCC(O)c1ccc(O)cc1</smiles>

Scheme 1. Molecular structure of $p$-synephrine ( ${ }^{*}$ : asymmetric carbon).

melting values. Indeed, it has been previously demonstrated that the temperature and the enthalpy of melting of a compound that degrades upon melting depend on the DSC scan rate since the degradation process can be bypassed at high scan rates [8].

\section{Experimental}

\subsection{Chemicals}

p-Synephrine was purchased from Sigma Aldrich, with a mass percentage purity higher than $98 \%$. The compound was used without further purification. The water content of $p$-synephrine was determined by the Karl-Fischer method using a DL 38 volumetric titrator from Mettler-Toledo (Switzerland). Methanol from Sigma Aldrich, with a mass purity higher than $99.9 \%$, was used as solvent. The moisture content was found to be less than $0.07 \%$.

\subsection{X-ray diffraction}

X-ray powder diffraction experiments were performed with a horizontally mounted cylindrical position-sensitive detector CPS-120 (Debye-Scherrer geometry, transmission mode) from INEL, using monochromatic $\mathrm{Cu} \mathrm{K} \alpha_{1}$ radiation $(\lambda=1.5406 \AA)$, selected with an asymmetric focusing incident-beam curved quartz monochromator. The generator power was set to $1.0 \mathrm{~kW}(40 \mathrm{kV}$ and $25 \mathrm{~mA}$ ). The detector consisted of 4096 channels providing angular step of $0.029^{\circ}(2)$ between $4^{\circ}$ and $120^{\circ}$. External calibration using the $\mathrm{Na}_{2} \mathrm{Ca}_{2} \mathrm{Al}_{2} \mathrm{~F}_{14}$ (NAC) cubic phase mixed with silver behenate was performed by means of cubic spline fittings. From that, each channel is converted in diffraction angle.

The samples were gently crushed before being introduced into Lindemann glass capillaries with $0.5 \mathrm{~mm}$ inner diameter, which were then rotated perpendicular to the X-ray beam direction in order to decrease as much as possible the effects of preferred orientations.

Crystal structure was determined with the reflex plus module of Materials Studio Modeling 5.5 [9]. First, the pattern was indexed by means of the peak picking option of the software package. Potential solutions for cell parameters and space group were found using the X-cell algorithm [10]. Then, a Pawley profile-fitting procedure was applied including refined cell parameters experimental profile fitting with pseudo-voigt function, zero shift and asymmetry Finger-Cox-Jephcoat function [11]. Distances, angles and torsions in the molecule were obtained via energy-minimization calculations with the forcite module using the Dreiding force field [12]. Then, a Monte-Carlo approach, included in the reflex plus module, was carried out in the direct space to solve the structure moving the molecule as a rigid-body and allowing the change of the chain torsion angles [13].

\subsection{Thermal analysis}

Differential scanning calorimetry and thermo-gravimetric analysis experiments were performed using an 822e thermal analyser, equipped with a FRS5 sensor, and a TGA 850 from MettlerToledo (Switzerland). The DSC and TGA experiments were carried out in the $25-300^{\circ} \mathrm{C}$ temperature range at different scan rates from 2 to $100^{\circ} \mathrm{C} \min ^{-1}$ under a constant nitrogen flow.

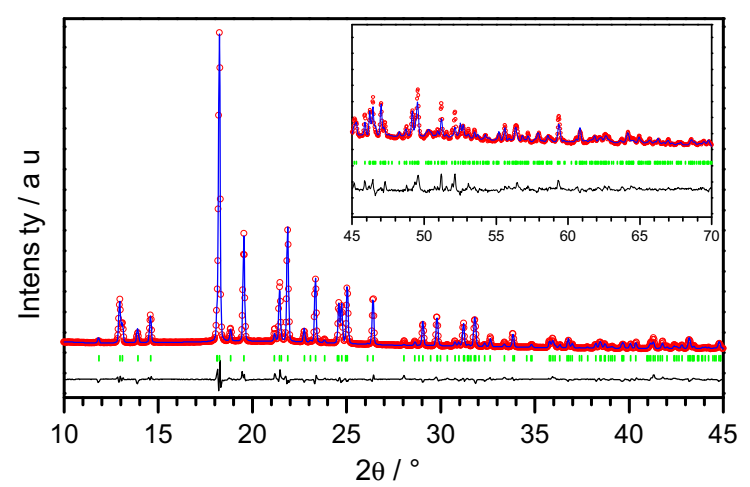

Fig. 1. Final Rietveld refinement of X-ray diffraction pattern of $p$-synephrine obtained at $294 \mathrm{~K}$. Blue line: experimental pattern, empty red circles: calculated pattern, green vertical bars: peak positions, black line: residual XRPD patterns. The insert corresponds to the scale for the data between $45^{\circ}$ and $70^{\circ}$ magnified 15 times. (For interpretation of the references to colour in this figure legend, the reader is referred to the web version of this article.)

Temperature and enthalpy calibration of the apparatus were carried out at $10^{\circ} \mathrm{C} \mathrm{min}^{-1}$. Indium and zinc were used for temperature and enthalpy calibration. The multiple thermocouple sensor technology of the device combined with furnace and sample tau lag calibration eliminates the influence of the heating rate on temperature and heat flux measurements [14]. The tau lag was calibrated for scan rates ranging from 2 to $100^{\circ} \mathrm{C} \mathrm{min}^{-1}$, using the procedure as described by the manufacturer. Regarding the enthalpy values, a relative standard uncertainty on the values was estimated at 5\%. For all the experiments, an empty aluminium pan was used as a reference. The melting temperatures were determined at the onset of the corresponding endotherms. p-Synephrine samples (approximately $2.5 \mathrm{mg}$ ) were weighed with a microbalance sensitive to $1 \mu \mathrm{g}$ and then introduced into a crucible with a perforated cover. The standard uncertainty on the temperatures was determined from the standard deviation, with 0.68 level of confidence, of three independent measurements performed for each scan rate.

\section{Results and discussion}

The crystal structure of $p$-synephrine was determined at room temperature $(294 \mathrm{~K})$. The title compound crystallizes in the monoclinic space group $\mathrm{P} 22_{1} / \mathrm{c}$ with $\mathrm{a}=8.8504 \pm 0.0011 \AA$, $\mathrm{b}=12.1166 \pm 0.0015 \AA, \quad c=9.7820 \pm 0.0011 \AA, \quad \beta=122.551 \pm 0.2^{\circ}$, with four molecules per unit cell $(Z=4)$. Since the space group is centrosymmetric, the asymmetric unit consists of one independent molecule $\left(Z^{\prime}=1\right)$. The translational mirror c (and center) is explained by the fact that the compound is a racemic compound. The agreement between observed and computed diffraction patterns is estimated by a reliability factor Rwp. The final Rietveld refinement (including Pawley refined parameters, rigidbody molecular units, torsions, preferred orientations and overall isotropic factor) converged to a final Rwp value of 6.98\% (Fig. 1). From the refinement, the density Dx of solid synephrine is found to be $1.256 \pm 0.001 \mathrm{~g} \mathrm{~cm}^{-3}$ at $294 \mathrm{~K}$.

All the above results are gathered in Table S1.

Rietveld refinement allowed us to propose the crystal structure presented in Fig. 2 and the asymmetric unit with atom numbering in Fig. S1. As shown in Fig. S1, a disorder between two positions of the hydrogen atoms of the hydroxyl group (011) and secondary amine (N8) leads to an occupancy factor of 0.5 for each. Each position makes a hydrogen bond in the crystal, as shown in Table S2.

The molecular structure is maintained through five intermolecular H-bonds (Table S2) directed along the rows [0 011$]$ and [011] (Fig. S2). The refinement also revealed two intra-molecular 


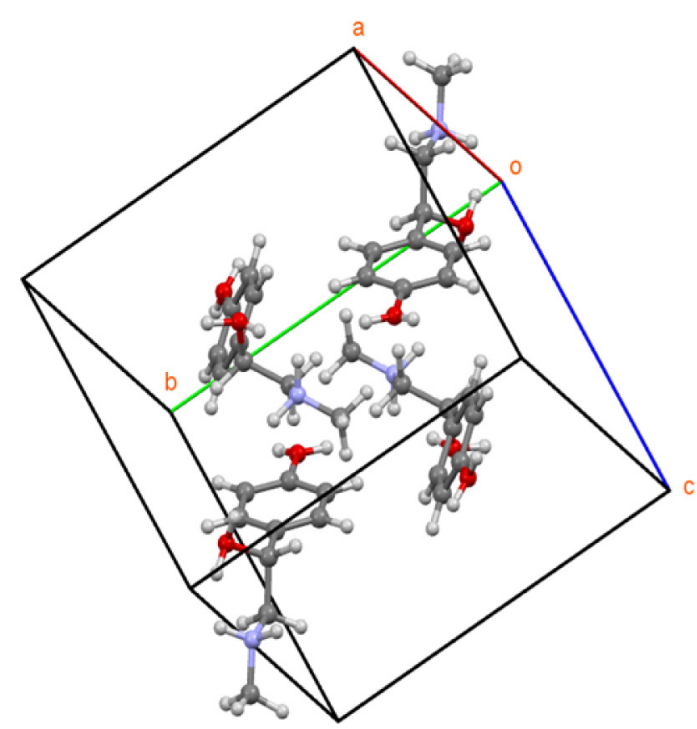

Fig. 2. Unit cell of $p$-synephrine

$\mathrm{H}$-bonds via N9 and 012. This double interaction is caused by the occupancy factor of 0.5 of the hydrogen on the secondary amine and the hydroxyl group.

The melting-degradation process of $p$-synephrine was evidenced by DSC and TGA experiments carried out, first of all, at $5{ }^{\circ} \mathrm{C} \mathrm{min}^{-1}$. The DSC curve (Fig. 3A) reveals an endothermic peak at $\sim 180^{\circ} \mathrm{C}$ and the TGA curve (Fig. 3B) indicates that the product degrades at the same time since a weight loss of approximately $17 \%$ can be observed. One can conclude that the endothermic peak actually corresponds to an apparent melting of $p$-synephrine, i.e. a simultaneous fusion and degradation process of synephrine. This phenomenon was confirmed by the abrupt return to baseline of the DSC signal followed by an exothermic peak (Fig. 3A, inset), characteristic of degradation upon melting. Still on heating, further degradation takes place continuously, as observed in Fig. 3. Indeed, a broad exothermic peak can be observed between 240 and $280^{\circ} \mathrm{C}$. This signal is correlated with an important weight loss observed from TGA experiment (Fig. 3B).

Increasing the DSC scan rate up to $100^{\circ} \mathrm{Cmin}^{-1}$, the apparent melting temperature shifts to high temperatures and the abrupt return to baseline disappeared. Hence, the two exothermic signals related to degradation are shifted to higher temperature (Fig. 4). This was confirmed by TGA experiments carried out at different scan rates since the signal related to the weight loss due to degradation is shifted to higher temperature while the degradation rate remains virtually the same. As far as the first exothermic peak (Fig. 4B) is concerned, it tends to disappear at high scan rates since degradation has moved to higher temperature.

As shown in Fig. 4, when increasing the DSC scan rate, the onset of the endothermic signal is shifted to higher temperature. This is explained by the fact that, at low scan rates, the lowering of the signal temperature is caused by the degradation which takes place simultaneously with melting. The apparent melting peak is then broadened and shifted to low temperatures due to mixing effect of the degraded product and the pure substance. When substances do not degrade upon melting, the melting temperatures are generally independent of the heating rate, as previously reported [8]. This is also true for eutectic reaction where the invariant eutectic temperature does not depend on the scan rate [15].

As previously reported, chemical reaction, such decomposition, occurring upon melting, is significantly shifted towards higher temperatures by increasing the heating rate $[8,16,17]$. A recent study performed by means of Fast Scanning Calorimetry has
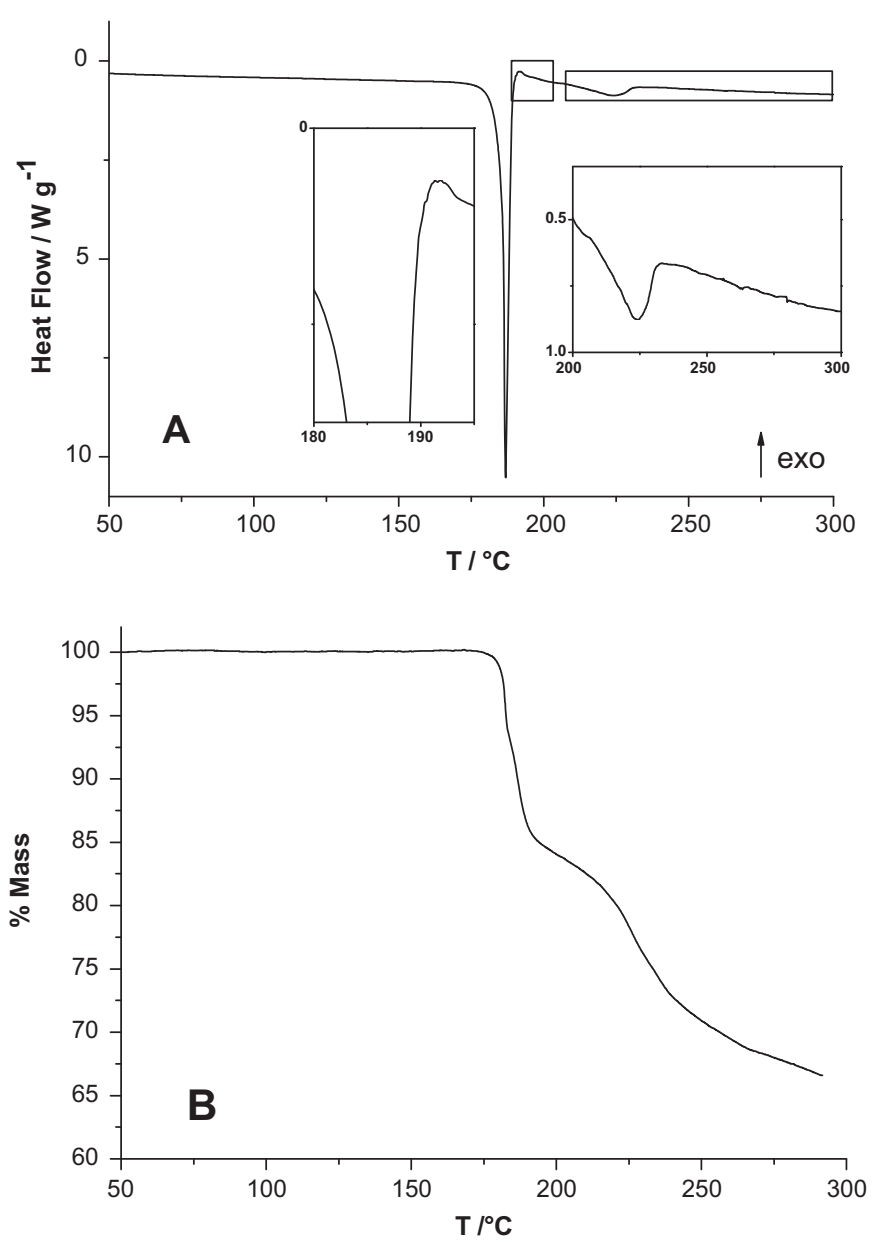

Fig. 3. DSC (A) and TGA (B) curves of $p$-synephrine recorded at $5{ }^{\circ} \mathrm{Cmin}^{-1}$. The inse of panel $A$ corresponds to the zoom of the degradation region between 175 and $300^{\circ} \mathrm{C}$.

demonstrated that a product which is used to degrade upon melting can melt without degrading [18]. In this case, the ultra fast heating rate screening allowed bypassing the degradation process upon melting. The degradation process occurred thus at higher temperature than the melting temperature.

The onset of the apparent melting temperature was reported as a function of the heating rate (Fig. 5A). The melting temperature increases with the scan rate to reach a plateau value at $199.8 \pm 1.3^{\circ} \mathrm{C}$ for high scan rates. This value is higher than the one previously reported in Ref. [7].

The same statement was established for the apparent melting enthalpy. The values plotted as a function of the scan rate (Fig. 5B) led to a constant value of $57 \pm 3 \mathrm{~kJ} \mathrm{~mol}^{-1}$, also deduced at high scan rates. This value differs from that reported in Ref. [7] $\left(99.7 \mathrm{~kJ} \mathrm{~mol}^{-1}\right)$ probably due to the fact that the experimental conditions are not identical. In our case, the DSC pans were perforated while, in the other case, the DSC experiments were conducted in hermetic pans. With a hermetically sealed pan, the gaseous degradation products formed upon heating are kept confined with non-degraded synephrine. As a consequence, upon heating, the pressure inside the sealed crucible increases and the nature and the number of phases in equilibrium are not the same as in the case where the solid sample is not in presence of gaseous substances.

The lower enthalpy values observed at low scan rates are explained by the superimposition of two effects: melting (positive energy value) and degradation (negative energy value). The more important the degradation, the higher the associated enthalpy. 

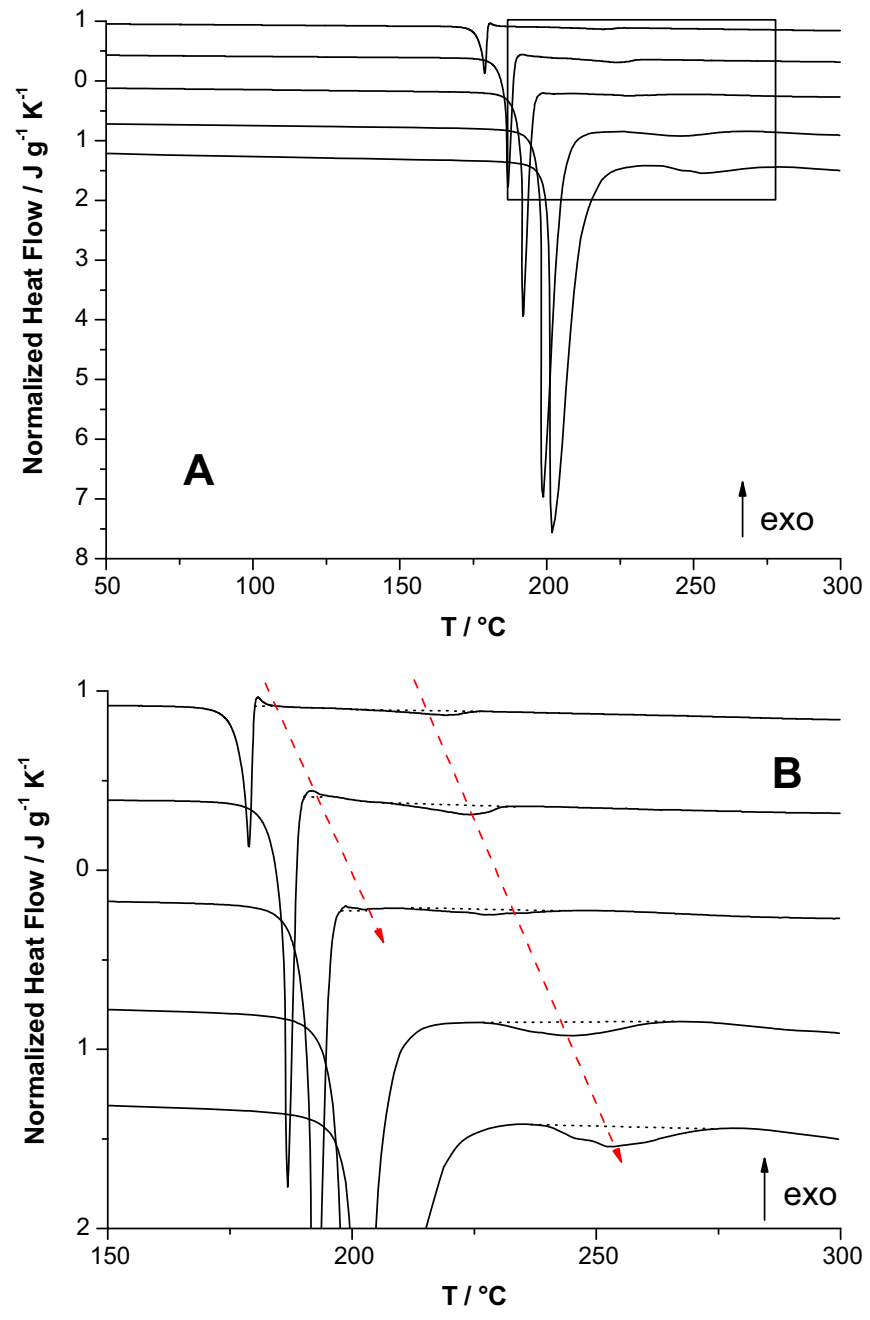

Fig. 4. (A) Selected normalized DSC curves at $2,5,10,30,50^{\circ} \mathrm{Cmin}^{-1}$ (from top to bottom). (B) Zoom of the DSC curves from (A) highlighting the endothermic heat effects due to degradation. Red arrows indicate the degradation shift to higher temperatures. (For interpretation of the references to colour in this figure legend, the reader is referred to the web version of this article.)

When increasing the scan rate, the degradation shifts to high temperature and then the contribution of the associated enthalpy is becoming weaker, which results in increasing the overall value.

Previous work on vitamin C [8], a compound which degrades upon melting, have shown that the melting data (temperature and enthalpy) obtained at high scan rates, were validated by the values obtained from the study of a heterogeneous system between vitamin $C$ and stearic acid, the latter being effective to protect the vitamin $C$ from its thermal degradation. Based on this conclusion, one can assume that the plateau values obtained for $p$-synephrine can be attributed to the "true" melting temperature and enthalpy values. Moreover, these values may be not altered by the rate of impurity present in the product (less than $2 \%$ ). In agreement with previously published results, taking into account a purity of $98 \%$, the standard deviation of the melting data of a compound could be slightly shifted depending on the type of the phase diagram considered $(0.2 \%$ and $0.5 \%$ in the case of solid solutions [19] and physical mixtures [20], respectively). These variations are then acceptable insofar as they fall within the determined uncertainties.
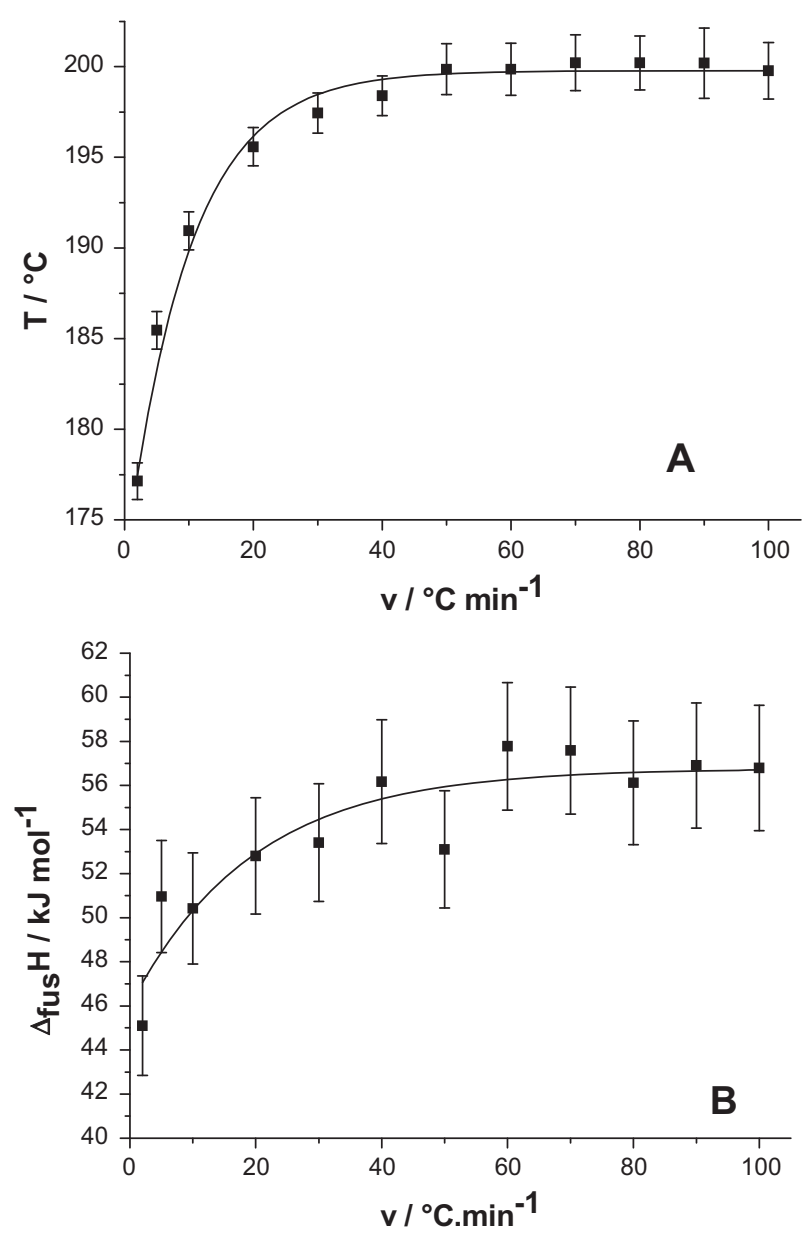

Fig. 5. Temperature (A) and enthalpy (B) of melting of $p$-synephrine as a function of the heating rate.

\section{Conclusion}

For the first time, the crystal structure of $p$-synephrine is porposed. The refinement from X-ray powder diffraction experiments demonstrates unambiguously that this compound is a racemic compound since the two enantiomers are connected by a center of symmetry [21]. The hypothesis of a pseudoracemate (solid solution) can then be excluded since, if it was the case, we could have the same probability to find either an L- or a D- enantiomer on a same site, resulting in a disordered structure. Here the only disorder is due to the hydrogen atoms (occupancy factor of 0.5 ). The melting characteristics of $p$-synephrine have also been determined. Since this compound degrades upon melting, thermal analyses were carried out at different scan rates in order to obtain, at high scan rates, the "true" temperature and enthalpy values of melting.

The establishment of the binary phase diagram between the two enantiomers would corroborate these crystallographic and thermodynamic results since the equimolar composition of the two enantiomers would appear as a true crystalline addition compound, i.e. a racemic compound with its own well-defined arrangement in the solid state and with its own melting temperature, different from the pure enantiomers melting properties.

The use of high DSC scan rates allowed separating melting and degradation to get the specific melting data. Although this was not the aim of this paper, identification of the $p$-synephrine degradants and the associated degradation mechanisms might be considered in further studies. 


\section{Author contributions}

The manuscript was written through contributions of all authors. All authors have given approval to the final version of the manuscript.

\section{Acknowledgements}

This work was financially supported by the ANR project "AlyPOTEC".

The authors thank Ms. K. Debbasch for language improvements on this manuscript, and Dr F. Collas, from Mettler-Toledo, for fruitful discussion and assistance on the DSC experiments at high scan rates.

We thank Dr S. Dufay (AGEPS, AP-HP) for the Karl-Fischer experiment.

\section{References}

[1] M.D. Arbo, E.R. Larentis, V.M. Linck, A.L. Aboy, A.L. Pimentel, A.T. Henriques, E. Dallegrave, S.C. Garcia, M.B. Leal, R.P. Limberger, Concentrations of p-synephrine in fruits and leaves of Citrus species (Rutaceae) and the acute toxicity testing of Citrus aurantium extract and p-synephrine, Food Chem. Toxicol. 46 (2008) 2770-2775.

[2] L.G. Rossato, V.M. Costa, R.P. Limberger, M. de, L. Bastos, F. Remião, Synephrine: from trace concentrations to massive consumption in weight-loss, Food Chem. Toxicol. 49 (2011) 8-16.

[3] M.D. Arbo, G.C. Schmitt, M.F. Limberger, M.F. Charão, Â.M. Moro, G.L. Ribeiro, E. Dallegrave, S.C. Garcia, M.B. Leal, R.P. Limberger, Subchronic toxicity of Citrus aurantium L. (Rutaceae) extract and p-synephrine in mice, Regul. Toxicol. Pharm. 54 (2009) 114-117.

[4] O. Ehrismann, An adrenaline-like preparation, Deut. Med. Wochenschr. 53 (1927) 1263.
[5] E.D. Bergmann, M. Sulzbacher, A new synthesis of 1-(m- and p-hydroxyphenyl)-2-methylaminoethanol ( $\mathrm{m}$ - and p-sympathol), J. Org. Chem. 16 (1951) 84-89.

[6] M. Asscher, A new synthesis of $\omega$-amino- $\rho$-hydroxyacetophenones and thei reduction to the corresponding aminoethanols, Recl. Trav. Chim. Pay. B. 68 (1949) 960-968.

[7] A. Pobudkowska, B.A. Jurkowska, M.A. Wiatrowski, Fluid Phase Equilibr. 406 (2015) 209-216.

[8] Y. Corvis, M.-C. Menet, P. Negrier, M. Lazerges, P. Espeau, The role of stearic acid in ascorbic acid protection from degradation: a heterogeneous system for homogeneous thermodynamic data, New J. Chem. 37 (2013) 761-768.

[9] Materials Studio Modeling 5.5. (http://accelrys.com/products/collaborativescience/biovia-materials-studio/).

[10] M.A. Neumann, X-cell: a novel indexing algorithm for routine tasks and difficult cases, J. Appl. Cryst. 36 (2003) 356-365.

[11] G.S. Pawley, Unit-cell refinement from powder diffraction scans, J. Appl. Cryst. 14 (1981) 357-361.

[12] B.D. Mayo, W.A. Goddard III, DREIDING: a generic force field for molecular simulations, J. Phys. Chem. 94 (1990) 8897-8909.

[13] G.E. Engel, S. Wilke, O. König, K.D.M. Harris, F.J.J. Leusen, PowderSolve-a complete package for crystal structure solution from powder diffraction patterns, J. Appl. Cryst. 32 (1999) 1169-1179.

[14] T. Kehl and G. van der Plaats, US Patent 5.033.866, (1991).

[15] Y. Corvis, M.-C. Menet, P. Espeau, New J. Chem. 39 (2015) 1938-1942.

[16] G.F.M. Pinheiro, V.L. Lourenço, K. Iha, Influence of the heating rate in the thermal decomposition of HMX, J. Therm. Anal. Calorim. 67 (2002) 445-452.

[17] M. Hurtta, I. Pitkänen, J. Knuutinen, Melting behaviour of D-sucrose, D-glucose and D-fructose, Carbohyd. Res. 339 (2004) 2267-2273.

[18] Y. Corvis, A. Wurms, C. Schick, P. Espeau, Vitreous state characterization of pharmaceutical compounds degrading upon melting by using fast scanning calorimetry, J. Phys. Chem. B 119 (2015) 6848-6851.

[19] R. Stolk, F. Rajabalee, M.H.G. Jacobs, P. Espeau, D. Mondieig, H.A.J. Oonk, Y. Haget, The RI-liquid equilibrium in the ternary system $n$-pentadecane $+n$-hexadecane $+n$-heptadecane. calculation of liquidus surface and thermal windows comparison with experimental data, CALPHAD 21 (1997) 401-410.

[20] Y. Corvis, P. Espeau, Incidence of chirality on the properties of mixtures containing an amide type anesthetic compound, Thermochim. Acta 539 (2012) 39-43.

[21] Y. Corvis, P. Negrier, S. Massip, J.-M. Leger, P. Espeau, Insights into the crystal structure, polymorphism and thermal behavior of menthol optical isomers and racemates, CrystEngComm 14 (2012) 7055-7064. 